\title{
LETTERS
}

\section{Pulmonary phaeohyphomycosis: a challenge to the clinician}

\section{To the Editor:}

Phaeohyphomycosis is a rare, slowly progressive infection caused by a heterogeneous group of imperfect black or dematiaceous fungi that are found in plants and soil, and contain a cytoplasmic melanin-like pigment, which appears to have aetiological significance by decreasing the susceptibility of these organisms to antifungal agents. A commonly recognised species included in this group is Cladosporium spp. [1]. Although it has been described as a pathogen in immunocompromised patients, there are no reports of lung infections caused by this agent.

We present the case of a 27-year-old non-smoking female chemical engineer who worked at a cork company (quality control, smelling cork stoppers daily), without relevant medical history who was admitted to the pulmonology department (Vila Nova de Gaia-Espinho Hospital Centre, Vila Nova de Gaia, Portugal) with dry cough, malaise and low fever for the previous week. On examination, she was in a good general condition without dyspnoea or fever. The chest was clear to auscultation and there was no significant lymphadenopathy or hepatosplenomegaly. The remainder of the physical examination was unremarkable.

On admission, blood tests showed an increased white blood cell count with a normal differential and increased C-reactive protein. Chest radiography revealed multiple bilateral nodular images, which were more abundant in the right lung (fig. 1a). Treatment with antibiotics (amoxicillin/clavulanic acid plus azithromycin) was started without clinical or radiological response. Chest tomography showed multiple, poorly defined, cotton-like opacities with a ground-glass halo of subpleural and peribronchovascular predominance, some with air bronchogram suggesting fungal infection (fig. 1b). Immunological studies were normal and HIV serology was negative. Fibreoptic bronchoscopy with bronchoalveolar lavage (BAL) was performed and the patient was started empirically on voriconazole as her clinical status was worsening (persistent fever and malaise) and fungal cultures were not yet available. Fibreoptic bronchoscopy was normal and BAL was negative for neoplastic cells, as well as mycobacterial and microbiological cultures. Fungal culture showed dark colonies and Cladosporium cladosporioides was identified (fig. 1c). After treatment with voriconazole for 1 week there was marked radiological and clinical improvement, and 1 month later the patient was asymptomatic with total radiological resolution.

Dematiaceous fungi often cause disease in the immunocompromised host, with the most common routes of infection being the skin, via traumatic inoculation, and the respiratory tract [2]. Cladosporium spp. are increasingly being recognised as opportunistic pathogens in solid-organ transplant recipients [3] and remains a significant cause of morbidity and mortality, particularly in lung transplant recipients [4].

Phaeohyphomycosis involving the paranasal sinuses, mucous and mucocutaneous membranes, subcutaneous tissues and the central nervous system (including brain abscesses, meningitis and mycotic aneurysms) have been reported [5-9]. Reports of dematiaceous fungi on the respiratory system include the incidental finding of $C$. cladosporioides cultured at autopsy from a previously existing lung cavity and the isolation of various species from nasal septa and/or colonisation of maxillary sinuses [6-10].

In this case of phaeohyphomycosis, the patient had an unusually large work-related exposure to cork by inhalation, there was a high radiological suspicion of fungal infection, there were no recognised predisposing conditions associated with humoral or cell-mediated immunodeficiency and C. cladosporioides was isolated on BAL fluid.

Cladosporium spp. is reported as being one of the fifth most common fungi present in wine cork microflora [11].

In our case report, an excellent response to treatment with voriconazole was noted (loading dose $400 \mathrm{mg}$ every $12 \mathrm{~h}$ on the first day for two doses followed on day 2 by maintenance treatment $200 \mathrm{mg}$ orally every $12 \mathrm{~h}$ for 4 weeks) and no hepatic dysfunction or adverse reactions occurred. In addition, the patient was advised to change her professional activity, which she did, and has remained well ever since (follow-up of 2 years).

To the best of our knowledge, this is the first reported case of isolated pulmonary phaeohyphomycosis caused by Cladosporium spp.

This case illustrates a rare work-related fungal lung infection in an immunocompetent patient, which stands out not only for its rarity but also for its prompt response to antifungal treatment, making it very important to pursue a specific diagnosis.

Dematiaceous fungi, well known by plant pathologists, pose a new challenge to the clinician. Although more frequent in immunocompromised hosts, it can also affect immunocompetent patients depending on the amount of spore exposure, as illustrated in this case.

Itraconazole is thought to be the drug of choice for the treatment of infections caused by dematiaceous fungi, although few 

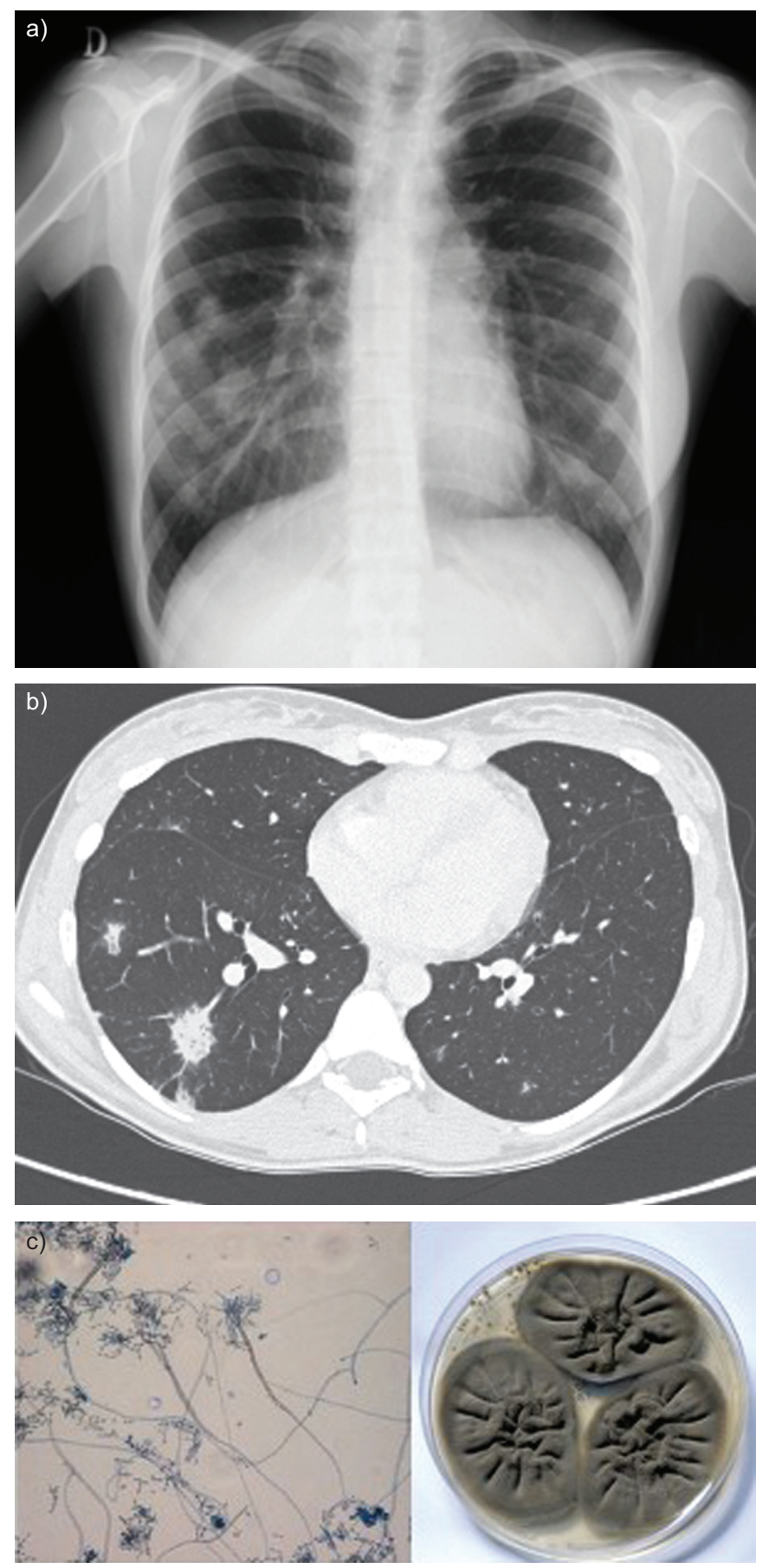

FIGURE 1. a) Chest radiograph at admission showing multiple bilateral nodular images, which are more abundant in the right lung. b) Chest computed tomography scan showing multiple, opaque cotton-like images, relatively poorly defined and outlining a ground-glass halo of subpleural and peribronchovascular predominance, some with air bronchogram, suggesting inflammatory/infectious changes, possibly due a fungal infection. c) Cladosporium cladosporioides colonies and microscopic features in the bronchoalveolar lavage mycological culture. Original magnification $\times 5$, Petri dish $90 \times 15 \mathrm{~mm}$. published data are available to aid therapy choices [10]. In our patient we empirically started treatment with voriconazole with an excellent response. Further studies are necessary to identify the best treatment options for phaeohyphomycosis.

\section{Ana Sofia Castro*, Ana Oliveira* and Virginia Lopes}

*Pulmonology Dept, Vila Nova de Gaia-Espinho Hospital Centre, Vila Nova de Gaia, and "Microbiology Dept, Oporto Hospital Centre, Porto, Portugal.

Correspondence: A.S. Castro, Pulmonology Dept, Centro Hospitalar, Vila Nova de Gaia-Esphino, Rua Conceição Fernandes, 4434-502, Vila Nova de Gaia, Portugal. E-mail: anasfcastro@gmail.com

Statement of Interest: None declared.

Provenance: Submitted article, peer reviewed.

\section{REFERENCES}

1 Al-Doory Y, Wagner G. Dematiacea: agents of chromomycosis and phaeohyphomycosis. In: Gilligan PH, Smiley ML, Shapiro DS, eds. Infectious Diseases and Medical Microbiology. 2nd Edn. Philadelphia, WB Saunders Co., 1986; pp. 602-605.

2 Fothergill A. Identification of dematiaceous fungi and their role in human disease. Clin Infect Dis 1996; 22: Suppl. 2, S179-S184.

3 Singh N, Chang F, Gayowski $\mathrm{T}$, et al. Infections due to dematiaceous fungi in organ transplant recipients: case report and review. Clin Infect Dis 1997; 24: 369-374.

4 Silveira F, Husain S. Fungal infections in lung transplant recipients. Curr Opin Pulm Med 2008; 14: 211-218.

5 Barenfanger J, Ramirez F, Tewari R, et al. Pulmonary phaeohyphomycosis in a patient with hemoptysis. Chest 1989; 95: 11581160.

6 Kwon-Chung KJ, Swartz IS, Rybak BJ. A pulmonary fungus ball produced by Cladosporium cladosporoides. Am J Clin Pathol 1975; 64: 564-568.

7 Horre R, de Hoog GS. Primary cerebral infections by melanized fungi: a review. In: de Horre GS, ed. Studies in Mycology \#43. Ecology and Evaluation of Black Yeasts and Their Relatives. Baarn, Centralbureau Voor Schimmel, 1999; pp. 176-193.

8 Sobol SM, Love RG, Stutman HR, et al. Phaeohyphomycosis of the maxilloethmoid sinus caused by Dreschslera spicifera: a new fungal pathogen. Laryngoscope 1984; 64: 620-627.

9 Berry AJ, Kerkering TM, Giordano AM, et al. Phaeohyphomycotic sinusitis. Ped Inf Dis 1984; 3: 150-152.

10 Gregg K, Pursell K. Cladosporium esophagitis after liver transplantation: case report and review of the literature. Infect Dis Clin Prac 2011; 19: 158-160.

11 Daria Fumi M, Galli R. Identificazione al microscopio ottico di muffe presenti su tappi: Significato nel controllo di qualità [Optical microscope identification of moulds on corks and its meaning in quality control]. Industrie delle Bevande 2004; 193: $421-425$ 